\title{
Can Stock Index Future Really Stabilize Stock Market? The Evidence from Chinese Stock Market
}

\author{
Chunli Zhang ${ }^{1} \&$ Lixiong Yang ${ }^{2}$ \\ ${ }^{1}$ School of Economics, Northwest University for Nationalities, Lanzhou, China \\ 2 School of Management, Lanzhou University, Lanzhou, China \\ Correspondence: Lixiong Yang, School of Management, Lanzhou University, Lanzhou 730000, China.
}

Received: January 27, 2016

Accepted: February 22, 2016

Online Published: March 1, 2016

doi:10.5430/ijba.v7n2p16

URL: http://dx.doi.org/10.5430/ijba.v7n2p16

Supported by the Fundamental Research Funds for the Central Universities (China) under Grant No. 31920150119.

\begin{abstract}
The financial theory shows that future markets can stimulate the information production, and therefore provide more information for uninformed traders, hence to stabilize the stock market. This paper investigates whether the Chinese CSI300 index futures can stabilize the Chinese stock market. By using the econometric approach of Bai (2003) and Stock and Watson (2011) to estimate the latent global factor from panel data of international stock markets, this paper controls the economic fundamentals and employs the equal variance test of Yang et al. (2014) to compare the volatility of the CSI300 stock index before and after the appearance of CSI300 index futures. We find that CSI300 index futures can help to stabilize the Chinese stock market significantly.
\end{abstract}

Keywords: global factor, the equal variance test, index future, volatility

\section{Introduction}

One of the most important functions of the future market is to provide information on resource allocation, that is, to encourage the production of information and facilitate the information transmission. Grossman (1977) showed that the future market, as a platform for information interchange, can give returns to people who collect and analyze information, and then stimulate them to invest in information gathering. He also pointed out that in an economy with spot market alone the judgment difference in beliefs about next period's price between the informed and uninformed stimulates the future trading. Uninformed traders can use the spot price as a statistic which reveals some of the informed traders' information with a future market.

Another important function of future market is information acquisition and aggregation. Price should be related to information of every participant and reflect all of the information of every participant. Based on this observation, Grossman (1976) studied the ability of information aggregation of the stock price in the stock market where there is a risk-free asset and $\mathrm{n}$ traders who have partial information, and found that the quality of information reflected by prices is better than that obtained by each trader. Hellwig (1980) pointed out that, in the Grossman's model, each trader is schizophrenic, that is, if the price can aggregate the information held by all traders, then one should discard his information and use the information reflected by price. On the other hand, if everyone didn't use his information, then price cannot reflect traders' information. To overcome this problem, Hellwig (1980) extended Grossman's model to a "big economy" where each trader is price taker, and concluded that price transmission in stock market depends on the existence of lots of independent information sources. Therefore, we can expect that the future market can stabilize the spot market.

In the empirical literature, it is commonly realized that future market can decrease the cost of information and facilitate the uninformed traders, hence reduce the volatility of stock market and increase the efficiency of the allocation of capital. Mackenzie et al. (2001) found that, in the Sydney futures exchange, the system risk and conditional volatility decrease significantly after the associated future is issued. Corredor et al. (2002) and Drimberas et al. (2007) studied the Spain and Greek stock markets respectively and obtained the similar conclusions.

However, another strand of literature support that the future markets may increase the volatility of the target stock 
price. Chang et al. (1999) analyzed the Nikkei Stock Index and found that the constituent stocks become more fluctuate. Bae et al. (2004) studied the South Korean market and concluded that the index future increases the volatility of the stock market. More recently, Wang et al. (2009) considered the relationship between futures and stock markets in Hong Kong, and obtained the similar results. Therefore, the empirical literature gives us the mixed results.

Compared with other stock markets, Chinese stock market is very young, and was totally without short selling. Since April 16, 2010, securities margin trading and the CSI300 index futures were issued, the market of unilateralism in China's stock market is ended. However, the amplitude of Chinese stock market is frequently more than 5\%. So, do the CSI300 index futures stabilize or deteriorate the volatility of stock market? Which is the source of the serious volatility, the index futures or fundamentals? This paper is to focus on the upper questions.

Gregory and Head (1999) indicated that the business cycle is driven by global and Country specific factors. Bekaet et al. (2009) modeled the stock returns as global and local factors. The literature has realized that it is a method to explain economic phenomena by using a few factors (Bai, 2003), for example the classical CAPM model and APT model. Bai (2003), Stock and Watson (2011), and Bai and NG (2013) derived the econometric approach to estimate the latent factors consistently using the panel data.

This paper studies how the CSI300 index futures affect the Chinese stock market by employing the equal variance test proposed by Yang et al. (2013) and using the factor model to control the economic environments.

The remainder of the paper is organized as follows. Section 2 presents the methodology. This section also investigates the finite sample properties of the equal variance test. Section 3 presents empirical results. Finally, Section 4 provides the concluding remarks.

\section{The Methodology}

\subsection{Estimating the Latent Factors under the Panel Data}

Following Bai (2003), consider the following model:

$$
X_{t}=\Lambda F_{t}+e_{t}, t=1,2, \ldots, T
$$

in which $X_{t}=\left(X_{1 t}, X_{2 t}, \ldots, X_{N t}\right)^{\prime}, \Lambda=\left(\lambda_{1}, \lambda_{2}, \ldots, \lambda_{N}\right)^{\prime}$, and $e_{t}=\left(e_{1 t}, e_{2 t}, \ldots, e_{N t}\right)^{\prime}$.

Equation (1) can also be rewritten as:

$$
\underline{X}_{i}=F \lambda_{i}+\underline{e}_{i}, i=1,2, \ldots, N
$$

in which, $\underline{X}_{i}=\left(X_{i 1}, X_{i 2}, \ldots, X_{i T}\right)^{\prime}, F=\left(F_{1}, F_{2}, \ldots, F_{T}\right)^{\prime}$, and $\underline{e}_{i}=\left(e_{i 1}, e_{i 2}, \ldots, e_{i T}\right)^{\prime}$.

We can estimate the latent factors by minimizing:

$$
V(r)=\min _{\Lambda, F}(N T)^{-1} \sum_{i=1}^{N} \sum_{t=1}^{T}\left(X_{i t}-\lambda_{i}^{\prime} F_{t}\right)^{2}
$$

Denote $\Lambda^{0}$ and $F^{0}$ be the true values of $\Lambda$ and $F$. Bai (2003) showed, under some assumptions, that: for the estimators $\tilde{F}$ and $\tilde{\Lambda}$, there exists an invertible matrix , say $H$, such that $\tilde{F}$ is a consistent estimator of $F^{0} H^{1^{-1}}$, and $\tilde{\Lambda}$ is a consistent estimator of $\Lambda^{0} H$. These results are summarized in Theorem 1.

Theorem 1: under appropriate assumptions, if $N, T \rightarrow \infty, \sqrt{N} / T \rightarrow 0$, then for arbitrary $t$, we have :

$$
\sqrt{N}\left(\tilde{F}_{t}-H^{\prime} F_{t}^{0}\right) \stackrel{d}{\longrightarrow} N(0, \Omega)
$$

in which, $\Omega$ is a matrix related to latent factors, which is given by Bai (2003, Page 12).

Therefore, we can compare the volatility of stock market after and before the CSI 300 futures were issued by using 
the estimator $\tilde{F}_{t}$ to control the economic environment.

\subsection{The Equal Variance Test}

Lee et al. (2012) built an unequal variance test to study the co-integration degree of co-integration model. But the unequal variance test (Lee et al., 2012) assumed that data of cross section are independent. Yang et al. (2014) proved that the unequal variance test could reject wrongly the true null hypothesis when the assumption of independent cross section was violated. Then under the assumption of correlated cross section, the paper, following Yang et al. (2014) shows a new equal variance test which has better finite sample performance.

Assume $x_{t}, y_{t}$ are detrended time series:

$$
\begin{gathered}
x_{t}=\mu_{x}+\boldsymbol{\beta}^{\prime} \mathbf{Z}_{t}+v_{t} \\
y_{t}=\mu_{y}+\boldsymbol{\beta}^{\prime} \mathbf{Z}_{t}+\varsigma_{t}, t=1,2, \ldots, T
\end{gathered}
$$

in which, $\mu_{x}, \mu_{y}$ are constant terms, $\mathbf{Z}_{t}$ is explanatory variable, and $v_{t}, \varsigma_{t}$ are disturbance terms.

Before constructing the test and performing statistical inference, we must be precise about the dependence structure of the squared errors $\left\{\left(v_{t}^{2}, \varsigma_{t}^{2}\right)^{\prime}\right\}_{t=0}^{\infty}$ in Eqs. (5) and (6) to ensure the validity of a functional central limit theorem. In modeling the dependence or memory of a time series in econometrics, nonparametric methods, of which martingale difference and mixing are perhaps most commonly used, are very popular because of their flexibility and model-free characteristics. In constructing the variance test, Lee et al. (2012) assumed that the squared errors are cross-sectionally uncorrelated adapted mixingale where the mixingale process has attributed both mixing processes and martingale difference processes. (Note 1) However, martingale differences are sequences of a rather special kind and many important dependent processes are not mixing, e.g., infinite moving average $(\mathrm{MA}(\infty))$ under general conditions and stable first-order linear autoregressive models with Bernoulli-distributed i.i.d. shocks (Yang et al., 2014). The mixing condition is also difficult or impossible to check because establishing conditions where uniform mixing holds is harder, while the best known sufficient condition (e.g., Davidson 1994, Theorem 14.4) requires the shock process to be bounded with probability 1 , ruling out normality for example. In addition, there is considerable evidence to model the conditional variance and covariance in financial time series by using a GARCH-type model since Engle (1982) and Bollerslev (1986). Thus, the squared errors in Eqs. (5) and (6) may be governed by a GARCH model. Unfortunately, it is not known under what conditions GARCH processes are mixing (Hansen, 1991). Therefore, the mixing assumption might not be the best candidate in modeling the squared errors.

Instead of assuming that the squared errors are adapted mixingale and cross-sectionally uncorrelated, the current paper employs the near-epoch dependence (NED). We also allows for cross-sectional dependence between the squared errors. The NED assumption has the benefits of holding in cases where mixing fails and of being potentially. In order to give a more convenient statement in what follows, we first introduce the specific definition of NED.

Definition 1 (vector-form NED) (Yang, 2014):

Let $\quad \mathbf{z}_{t}\left(\ldots, e_{t-1}, e_{t}, e_{t+1}, \ldots\right)=\left(z_{1 t}\left(\ldots, e_{t-1}, e_{t}, e_{t+1}, \ldots\right), z_{2 t}\left(\ldots, e_{t-1}, e_{t}, e_{t+1}, \ldots\right)\right)^{\prime}$ be a $2 \times 1$ random vector sequence, which is a measurable function of the underlying mixing process $\left\{e_{s},-\infty<s<\infty\right\}$, where $e_{s}$ is an $\alpha$-mixing of size $-r /(r-2)$ for $r>2$ or $\phi-$ mixing of size $-r /(2 r-2)$ for $r \geq 2$. The process $\mathbf{z}_{t}=\left(z_{1 t}, z_{2 t}\right)^{\prime}$ is said to be $L_{p}$-NED on a mixing process $e_{t}$ for $p>0$ if

$$
\left|z_{1 t}-E_{t-m}^{t+m}\left(z_{1 t}\right)\right|^{p}+\left|z_{2 t}-E_{t-m}^{t+m}\left(z_{2 t}\right)\right|^{p} \leq d_{t} v(m),
$$

where $d_{t}$ is a sequence of positive constants, and $v(m) \rightarrow 0$ as $m \rightarrow \infty . \mathbf{z}_{t}=\left(z_{1 t}, z_{2 t}\right)^{\prime}$ is said to be $L_{p}$-NED of size $-u$ if $v(m)=O\left(m^{-u-\varepsilon}\right)$ for $\varepsilon>0$. 
To derive the asymptotic distributions of the proposed equal variance test, we need the following assumptions on the regression errors and their squared processes.

Assumption 1: The error process $\mathbf{u}_{t}=\left(v_{t}, \varsigma_{t}\right)^{\prime}$ is stationary and ergodic with $E\left(v_{t}, \varsigma_{t}\right)^{\prime}=(0,0)^{\prime}, E\left(v_{t}^{2}, \varsigma_{t}^{2}\right)^{\prime}=\left(\sigma_{v}^{2}, \sigma_{\varsigma}^{2}\right)^{\prime}$

Assumption 2: The squared error process $\mathbf{z}_{t}=\left(v_{t}^{2}-\sigma_{v}^{2}, \varsigma_{t}^{2}-\sigma_{\varsigma}^{2}\right)^{\prime}$ is $L_{2}$-NED of size $-\frac{1}{2}$ on a process $\left\{e_{t}\right\}_{t=-\infty}^{\infty}$, where $e_{t}$ is an $\alpha-$ mixing of size $-r /(r-2)$ for $r>2$ or $\phi-$ mixing of size $-r /(2 r-2)$ for $r \geq 2$. In addition, $\sup _{t}\left\|\mathbf{z}_{t}\right\|_{r}<\infty$.

These assumptions are general enough to enable us to apply the central limit theorem to the vector of squared regression errors (i.e., $\mathbf{z}_{t}$ ) and accommodate a variety of possible processes of the squared errors, including GARCH. Assumption 1 enables us to employ the law of large numbers to estimate the variances of $v_{t}$ and $\varsigma_{t}$ and it also restricts $v_{t}^{2}$ and $\varsigma_{t}^{2}$ to be $L_{2}$-bounded. This in turn leads to the existence of the global variance of the squared cointegrating errors in Eqs. (5) and (6). Assumption 2 allows for the cross-sectional dependence and the auto-correlation of the squared errors.

Under Assumptions 1 and 2, Yang et al. (2014) show the following theorem.

Theorem 2: Under the null hypothesis of equal variance $H_{0}: \sigma_{v}^{2}=\sigma_{\varsigma}^{2}$, the test statistic $Z_{v}$ is asymptotically distributed as functional of Brownian motion:

$$
Z_{v}=\frac{T^{1 / 2}\left[\hat{\sigma}_{v}^{2}-\hat{\sigma}_{\varsigma}^{2}\right]}{\hat{M}_{v}} \stackrel{d}{\longrightarrow} \frac{W(1)}{\left\{\int_{0}^{1}[W(r)-r W(1)]^{2} d r\right\}^{1 / 2}}
$$

where $\hat{M}_{v}^{2}=\frac{1}{T} \sum_{[T r]=1}^{T} \hat{S}_{[T r]}^{v 2}$, in which $\hat{S}_{[T r]}^{v}=T^{-1 / 2} \sum_{s=1}^{[r T]}\left(\hat{v}_{s}^{2}-\hat{\zeta}_{s}^{2}-\hat{d}^{v}\right)$ and $\hat{d}^{v}=\frac{1}{T} \sum_{s=1}^{T}\left(\hat{v}_{s}^{2}-\hat{\zeta}_{s}^{2}\right)$.

This test statistic has a nonstandard asymptotic distribution and is free of nuisance parameters. The critical values of the test can be computed using simulations, and are tabulated in Table 1.

Table 1. The critical values of the functionals of browian motion in Eq.(8)

\begin{tabular}{lcrrrrrrrr}
\hline \hline & $1 \%$ & $2.50 \%$ & $5 \%$ & $10 \%$ & $50 \%$ & $90 \%$ & $95 \%$ & $97.5 \%$ & $99 \%$ \\
\hline $\mathrm{T}=25$ & -8.612 & -6.796 & -5.366 & -3.877 & -0.021 & 3.881 & 5.338 & 6.792 & 8.596 \\
$\mathrm{~T}=50$ & -8.602 & -6.753 & -5.319 & -3.869 & -0.010 & 3.893 & 5.367 & 6.822 & 8.586 \\
$\mathrm{~T}=100$ & -8.560 & -6.701 & -5.297 & -3.867 & 0.000 & 3.855 & 5.273 & 6.688 & 8.558 \\
$\mathrm{~T}=250$ & -8.545 & -6.720 & -5.295 & -3.853 & 0.012 & 3.884 & 5.318 & 6.725 & 8.551 \\
$\mathrm{~T}=500$ & -8.600 & -6.761 & -5.314 & -3.873 & 0.006 & 3.898 & 5.321 & 6.751 & 8.592 \\
$\mathrm{~T}=1000$ & -8.598 & -6.748 & -5.351 & -3.864 & 0.002 & 3.901 & 5.352 & 6.761 & 8.597 \\
$\mathrm{~T}=5000$ & -8.542 & -6.715 & -5.364 & -3.865 & 0.023 & 3.889 & 5.363 & 6.715 & 8.551 \\
\hline
\end{tabular}

Notes: The Monte Carlo simulation is used to calculate the critical value of the equal variance test, based on 100,000 replications. The Wiener process, $\mathrm{W}(\mathrm{r})$ is approximated by normalized sums of i.i.d. $\mathrm{N}(0,1)$ pseudo random deviates. The simulations were written in the GAUSS programming language. The standard errors of critical values are reported in Appendix D which confirm that simulating 100,000 Monte-Carlo replications is statistically sufficient. 


\subsection{The Finite Sample Properties of the Equal Variance Test}

This paper employs the Bai's (2003) method to control the economic fundamentals, and uses the equal variance test to compare the volatility of the Chinese stock market before and after the CSI300 index futures were issued. The performance of the equal variance test determines the validity of the empirical results. Therefore, we next examine the equal variance tests proposed by Lee et al. (2012) and Yang et al. (2014). Consider the following data generating processes:

$$
\begin{aligned}
& x_{t}=a f_{t}+b v_{t-1}+v_{t} \\
& y_{t}=c f_{t}+d \varsigma_{t-1}+\varsigma_{t}
\end{aligned}
$$

And we employ the variance tests to the hypothesis,

$$
H_{0}: \sigma_{x}^{2}=\sigma_{y}^{2} \text { v.s. } H_{1}: \sigma_{x}^{2} \neq \sigma_{y}^{2}
$$

where $f_{t}, v_{t}$ and $\zeta_{t}$ are mutually independent and assumed to be i.i.d.N $(0,1) . f_{t}$ is the common effect of the process $v_{t}$ and $\zeta_{t}$. To compare the finite sample properties of the variance tests, we focus on two scenarios: the cross-sectionally independent and the cross-sectionally dependent case. In this set-up, $a$ and $c$ are used to control the cross-sectionally dependence, and if $a=c=0$, the DGP degenerates to the cross-sectionally independent, but serially correlated case. $b$ and $d$ are used to describe the serial correlation, where $b, d \in[0,1)$. It is also worthy to note that, for other sample size, the finite sample properties of the tests are generally similar

\begin{tabular}{|c|c|c|c|c|c|c|c|c|c|c|c|}
\hline \multirow[b]{2}{*}{$(b, d)$} & \multicolumn{5}{|c|}{ Cross-sectionally independent case: size } & \multicolumn{6}{|c|}{ Cross-sectionally independent case: power } \\
\hline & $(0.1,0.1)$ & $(0.5,0.5)$ & $(0.75,0.75)$ & $(0.9,0.9)$ & $(0.98,98)$ & $(0.1,0.2)$ & \multicolumn{2}{|c|}{$(0.1,0.3)$} & $(0.1,0.4)$ & $(0.1,0.5)$ & $(0.1,0.6)$ \\
\hline Lee & 0.000 & 0.005 & 0.027 & 0.089 & 0.214 & 0.006 & 0.0 & & 0.339 & 0.708 & 0.994 \\
\hline \multirow[t]{2}{*}{ Yang } & 0.049 & 0.051 & 0.048 & 0.050 & 0.056 & 0.090 & 0.2 & & 0.599 & 0.894 & 1.000 \\
\hline & \multicolumn{11}{|c|}{ Cross-sectionally dependent case: size } \\
\hline$(a, b)$ & $(1,0.1)$ & $(1,0.75)$ & $(1,0.9)$ & $(1,0.95)$ & $(1,0.99)$ & $(5,0.1) \quad($ & $(5,0.75)$ & $(5,0.9)$ & $(5,0.95)$ & & $(5,0.975)$ \\
\hline$(\mathrm{c}, \mathrm{d})$ & $(1,0.1)$ & $(1,0.75)$ & $(1,0.9)$ & $(1,0.95)$ & $(1,0.99)$ & $(5,0.1)$ & $(5,0.75)$ & $(5,0.9)$ & $(5,0.95)$ & & $(5,0.975)$ \\
\hline Lee & 0.000 & 0.012 & 0.040 & 0.101 & 0.264 & 0.000 & 0.000 & 0.000 & 0.003 & & 0.005 \\
\hline \multirow[t]{2}{*}{ Yang } & 0.055 & 0.058 & 0.047 & 0.058 & 0.055 & 0.044 & 0.051 & 0.053 & 0.047 & & 0.053 \\
\hline & \multicolumn{11}{|c|}{ Cross-sectionally dependent case: power } \\
\hline$(a, b)$ & $(1,0.1)$ & $(1,0.1)$ & $(1,0.1)$ & $(1,0.1)$ & $(1,0.1)$ & $(5,0.1)$ & $(5,0.1)$ & $(5,0.1)$ & $(10,0.1)$ & & $(10,0.1)$ \\
\hline$(\mathrm{c}, \mathrm{d})$ & $(1,0.2)$ & $(1,0.3)$ & $(1,0.4)$ & $(1,0.5)$ & $(1,0.7)$ & $(5,0.2)$ & $(5,0.3)$ & $(5,0.4)$ & $(10,0.2)$ & & $(10,0.3)$ \\
\hline Lee & 0.002 & 0.026 & 0.302 & 0.741 & 1.000 & 0.000 & 0.000 & 0.093 & 0.000 & & 0.000 \\
\hline Yang & 0.104 & 0.348 & 0.711 & 0.935 & 1.000 & 0.338 & 0.895 & 0.983 & 0.721 & & 0.977 \\
\hline
\end{tabular}
although they are not reported here to save space. The finite sample properties for $\mathrm{T}=100$ are reported in Table 2 .

Table 2. The finite sample properties of the variance tests

Notes: The tests were one-sided with the nominal size set at $5 \%$, and were conducted for sample size $\mathrm{T}=100$ using 1000 replications. "Lee" denotes the test of Lee et al. (2012), and "New" denotes the variance test proposed in this paper.

The simulations indicate that: (1) the size control of the variance test of Lee et al. (2012) depends strongly on the serial correlation, thus a strong serial correlation can induce a spurious rejection of the null, while the proposed variance test has relatively good size; (2) a violation of the cross-sectionally uncorrelated squared errors can invalidate the variance test of Lee et al. (2012), especially in the cases where the squared errors are strongly 
cross-sectionally dependent. However, the proposed variance test can be used to achieve satisfactory performance. This paper therefore employs the equal variance test proposed by Yang et al. (2014) to investigate the volatility of stock market.

\section{Empirical Study}

\subsection{Econometric Model Setup}

This paper employs the factor model to control the economic fundamentals, hence discriminate the volatility associated with the CSI300 futures and the volatility related to economic fundamentals. First, we use the panel data of global stock markets to estimate the global factor:

$$
r_{i}=\lambda_{i} f_{t}^{\text {global }}+e_{i}
$$

in which $r_{i}$ is the return of stock market of country $i, f_{t}^{\text {global }}$ is the global factor. $\lambda_{i}$ is the factor loading. $e_{i}$ is the idiosyncratic risk of country $i$.

The econometric method proposed by Bai (2003) can be used to estimate the global factor, $f_{t}^{\text {global }}$, consistently.

We then consider the following factor-augmented model:

$$
r_{c h, t}=c+\alpha \Delta \hat{f}_{t}^{\text {global }}+\beta \Delta x_{c h, t}+e_{c h, t}
$$

in which $r_{c h, t}$ denotes the daily data of CSI300 index, $\hat{f}_{t}^{\text {global }}$ is the estimated global factor, $x_{c h, t}$ is the China economic indicators, $e_{c h, t}$ is the error term.

Bai (2003), Stock and Watson (2011) and Bai and $\mathrm{Ng}$ (2013) pointed out that in the regression model (12), only if $\hat{f}_{t}^{\text {global }}=f_{t}^{\text {global }}+o_{p}\left(T^{-1 / 2}\right)$, then the estimated error of $\hat{f}_{t}^{\text {global }}$ can be neglected.

\subsection{Data}

To investigate the impact of CSI300 index futures on Chinese stock market, we focus on the CSI300 index. Since the CSI300 index was issued on April 8, 2005, we therefore choose the CSI300 index for China over the period April 8, 2005 to December 31, 2012. Meanwhile, to extract the global factor we choose the stock price indexes of the main stock markets: US, Japan, Germany, France, UK, India, Indonesia, Hongkong, Taiwan, Malaysia, Korea, Singapore and Australia. Because the China economic indicators are announced monthly, we employ the smooth technique to obtain the daily data. The data are sourced from the DataStream database.

\subsection{Empirical Results}

Figure 1 is the return of the global factor estimated from the international stock markets by econometric method proposed by Bai (2003). It is easily to see that the volatility of global factor has time-vary features. Therefore, to investigate the volatility of the Chinese stock market before and after the CSI300 index futures were issued, we have to control the global factor. 


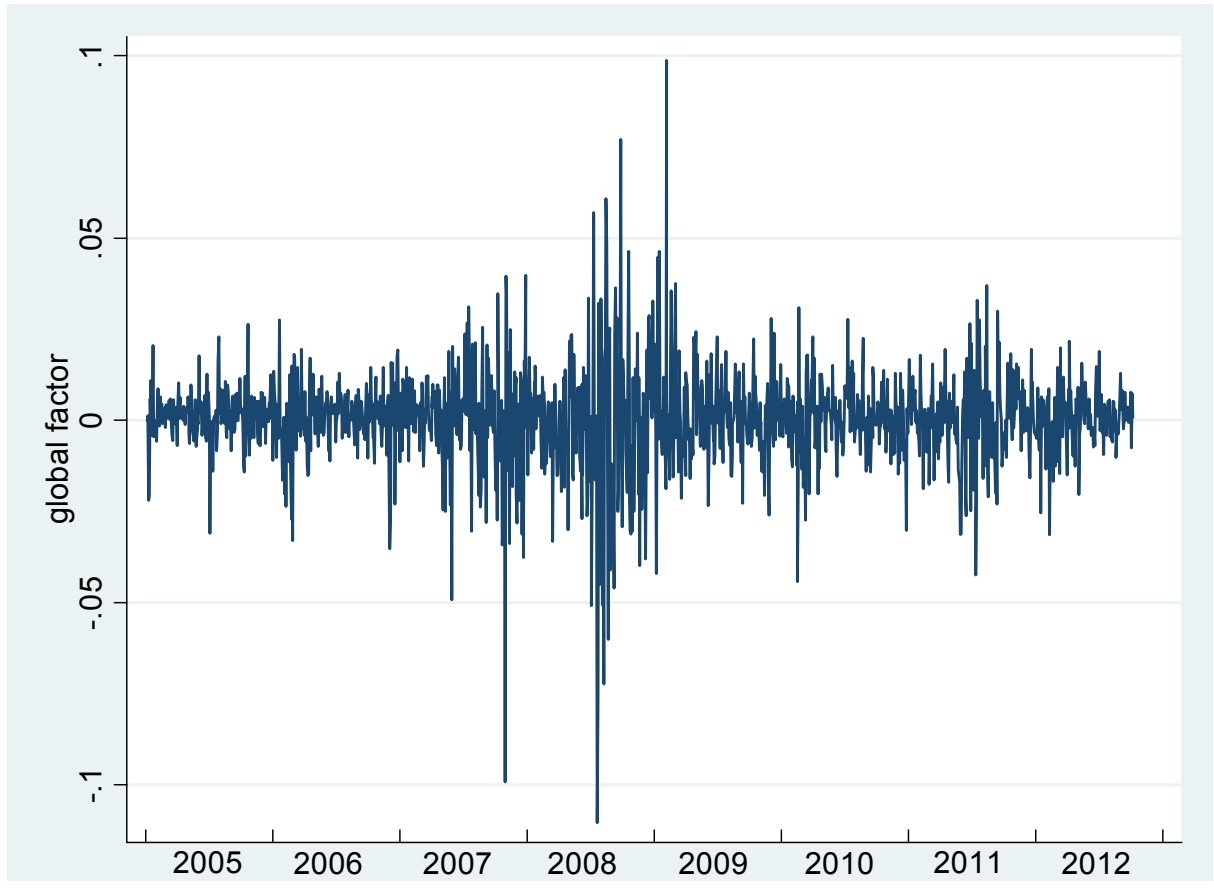

Figure 1. The global factor extracted from the international stock markets

Since the China Economic Indicators are announced monthly, we employ the smooth technique proposed by Jelinek and Mercer (1980) to approximate the daily data of China Economic Indicators. Figure 2 shows that the return of the Chinese idiosyncratic factor.

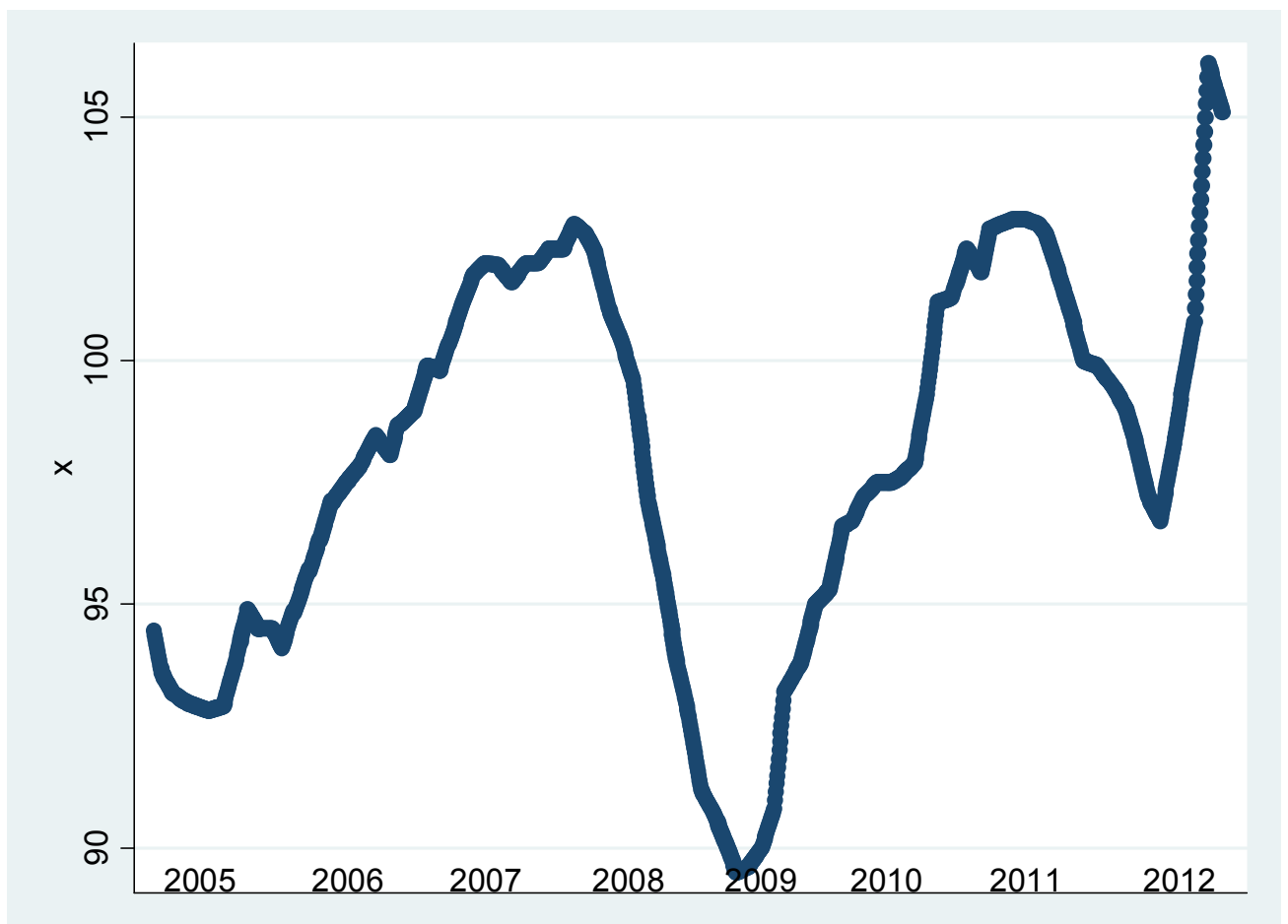

Figure 2. The idiosyncratic factor in China 
The sample is divided into pre-stage and post-stage after considering that the CSI300 index futures were issued on April 16, 2010. We can obtain the series of the return after controlling the global and idiosyncratic factors by employing the regression model (12). The regression results show that the global factor is significant at the level $1 \%$, while the idiosyncratic factor is insignificant at the level $10 \%$. That is, the Chinese stock market is seriously affected by the global factor, but not the idiosyncratic factor, which, maybe, implies the inefficiency of the Chinese stock market. On the other hand, it is important to control the global factor in investigating the volatility of the Chinese stock market. Controlling the global and idiosyncratic factor, the series of the return of CSI300 has no significant autocorrelation (See Figure 3).
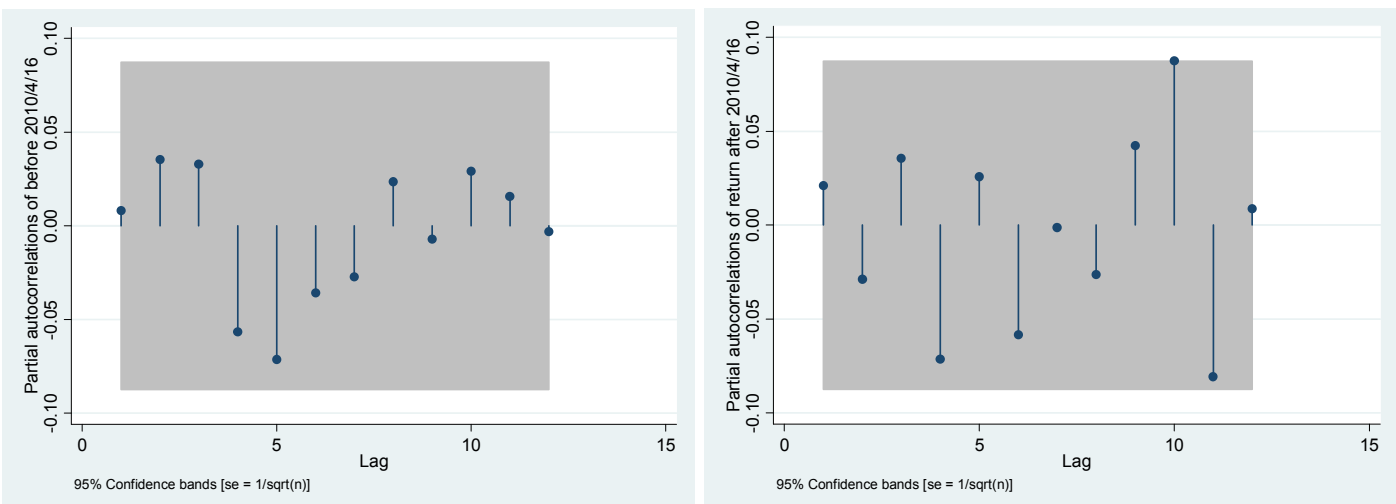

Figure 3. The partial auto-correlation of the CSI300 index after controlling the global and idiosyncratic factors

We next employ the equal variance test proposed by Yang et al. (2014) to compare the volatility of the return after controlling the economic fundamentals. By comparing the volatility of the stock market before and after the CSI300 index futures were issued we assess how the futures affect the stock market in China. Table 3 reports the results of the equal variance test. At the $2.5 \%$ significant level, we find the volatility of the Chinese stock market decreases after the CSI300 futures were issued. Therefore, we conclude that the index futures can stabilize the stock market.

Table 3. The volatility of the CSI300 after controlling economic fundamentals

\begin{tabular}{lcc}
\hline \hline & $\begin{array}{l}\text { Before the CSI 300 index } \\
\text { futures were issued }\end{array}$ & $\begin{array}{l}\text { After the CSI 300 index } \\
\text { futures were issued }\end{array}$ \\
\hline variance & 0.000553 & 0.0001654 \\
The equal variance test & & $7.509^{* *}$ \\
\hline \hline
\end{tabular}

Notes: $* *$ denotes the coefficient be significant at the level $2.5 \%$.

To check the robustness of the empirical results, we choose the log index as the focus and consider the following model:

$$
\log \left(S_{c h}\right)=c+\alpha \log \left(S_{\text {global }}\right)+\beta \log \left(x_{c h}\right)+e_{t}
$$

in which $\log \left(S_{c h}\right), \log \left(S_{\text {global }}\right)$ and $\log \left(x_{c h}\right)$ denote the logs of the Chinese CSI300 index, the global and idiosyncratic factors.

Similarly with the results shown in Table 3, we find that the global factor is significant at the level $1 \%$, while the idiosyncratic factor is not significant at $10 \%$. Further, the equal variance test also supports that the index futures can stabilize the stock market (Table 4). 
Table 4. The volatility of the log CSI300 after controlling economic fundamentals

\begin{tabular}{lcc}
\hline \hline & $\begin{array}{l}\text { Before the CSI 300 index } \\
\text { futures were issued }\end{array}$ & $\begin{array}{l}\text { After the CSI 300 index } \\
\text { futures were issued }\end{array}$ \\
\hline variance & 0.0164 & 0.0028 \\
The equal variance test & & $6.974^{* *}$ \\
\hline \hline
\end{tabular}

Notes: $* *$ denotes the coefficient be significant at the level $2.5 \%$.

On the other hand, since the return series can contain structural change which would affect the econometric analysis (Enders and Lee, 2012). This paper therefore employs the Fourier-function to approximate the structural change and constructs the following model:

$$
r_{c h, t}=c+\delta_{1} \sin \left(\frac{2 \pi k t}{T}\right)+\delta_{2} \cos \left(\frac{2 \pi k t}{T}\right)+\alpha \Delta \hat{f}_{t}^{\text {global }}+\beta \Delta x_{c h, t}+e_{c h, t}
$$

in which $k$ denotes a particular frequency. Following Enders and Lee (2012), we estimate (14) for all integer values of $k$ such that $1 \leq k \leq 5$. The regression with the smallest sum of squared residuals (SSR) yields $\hat{k}$. Based on $\hat{k}$ we can estimate the regression (14) and compare the volatility of the stock market after and before the CSI300 index futures were issued.

Table 5 reports the equal variance test based on model (14). We find the similar results and conclude that the empirical results are robust.

Table 5. The volatility of the CSI 300 based on Eq. (14)

\begin{tabular}{lcc}
\hline \hline & $\begin{array}{l}\text { Before the CSI 300 index } \\
\text { futures were issued }\end{array}$ & $\begin{array}{l}\text { After the CSI 300 index } \\
\text { futures were issued }\end{array}$ \\
\hline variance & 0.0005463 & 0.0001651 \\
The equal variance test & & $7.659^{* *}$ \\
\hline \hline
\end{tabular}

Notes: $* *$ denotes the coefficient be significant at the level $2.5 \%$.

We therefore conclude that the CSI300 index futures can help to stabilize the Chinese stock market. Mackenzie et al. (2001) found that, in the Sydney futures exchange, the system risk and conditional volatility decrease significantly after the associated future is issued. Corredor et al. (2002) and Drimberas et al. (2007) studied the Spain and Greek stock markets respectively and obtained the similar conclusions. This paper, using the equal variance test, shows that the similar results hold in Chinese stock market.

\section{Conclusions}

The literature shows that future markets can stimulate the information production, and therefore provide the more information for uninformed traders, hence to increase the informativeness of the price and stabilize the stock market. This paper investigates whether the Chinese CSI300 index futures can stabilize the Chinese stock market. By employing the econometric method proposed by Bai (2003), Stock and Watson (2011) and Bai and Ng (2013) to extract the latent global factor and the equal variance test proposed by Yang et al. (2014) to compare the volatility after and before the CSI300 futures were issued, we investigate whether the futures market could help to stabilize the stock market in China. We find that the volatility of the Chinese stock market decreases significantly after controlling the economic fundamentals. We therefore conclude that the CSI300 index futures can help to stabilize the Chinese stock market.

\section{References}

Admati, A. R., \& Stephen, A. R. (1985). Measuring investment performance in a rational expectations equilibrium model. Journal of Business, 1-26. http://dx.doi.org/10.1086/296280

Bae, S. C., Kwon T. H., \& Park, J. W. (2004). Futures trading, spot market volatility and market efficiency: The case of Korean index futures markets. Journal of Futures Markets, 24(12), 1195-1228.

Bai, J. (2003). Inferential theory for factor models of large dimensions. Econometrica, 71(1), 135-171. 
Bai, J., \& Ng, S. (2013). Principal components estimation and identification of static factors. Journal of Econometrics, 176, 18-29. http://dx.doi.org/10.1016/j.jeconom.2013.03.007

Bekaert, G., Hodrick, R. J., \& Zhang, X. (2009). International stock return comovements. The Journal of Finance, 64(6), 2591-2626. http://dx.doi.org/10.1111/j.1540-6261.2009.01512.x

Bollerslev, T. (1986). Generalized Autoregressive Conditional Heteroskedasticity. Joumal of Econometrics, 31(3), 307-327. http://dx.doi.org/10.1016/0304-4076(86)90063-1

Chang, E. C., Cheng J. W., \&Pinegar, J. M. (1999). Does futures trading increases stock market volatility? The case of the Nikkei stock index futures markets. Journal of Banking and Finance, 23(5), 727-753. http://dx.doi.org/10.1016/S0378-4266(98)00069-7

Davidson, J. (1994). Stochastic Limit Theory: An Introduction for Econometricicans. Oxford University Press, USA.

Davidson, J. (2002). Establishing conditions for the functional central limit theorem in nonlinear and semiparametric time series processes. Journal of Econometrics, 106(2), 243-269.

Dow, J., Goldstein, I., \& Guembel, A. (2006). Commitment to overinvest and price informativeness. EFA 2006 Zurich Meetings Paper. http://dx.doi.org/10.2139/ssrn.846245

Drimbetas, E., Sariannidis, N., \& Porfiris, N. (2007). The effect of derivatives trading on volatility of the underlying asset: evidence from the Greek stock market. Applied Financial Economics, 17(2), 139-148. http://dx.doi.org/10.1080/09603100500461702

Enders, W., \& Lee, J. (2012). A Unit Root Test Using a Fourier Series to Approximate Smooth Breaks. Oxford Bulletin of Economics and Statistics, 74(4), 574-599. http://dx.doi.org/10.1111/j.1468-0084.2011.00662.x

Engle, R. F. (1982). Autoregressive conditional heteroscedasticity with estimates of the variance of United Kingdom inflation. Econometrica, 50(4), 987-1007. http://dx.doi.org/10.2307/1912773

Gregory, A. W., \& Head, A. C. (1999). Common and country-specific fluctuations in productivity, investment, and the current account. Journal of Monetary Economics, 44(3), 423-451.

Grossman, S. J. (1977). The existence of futures markets, noisy rational expectations and informational externalities. The Review of Economic Studies, 44(3), 431-449. http://dx.doi.org/10.2307/2296900

Hellwig, M. F. (1980). On the aggregation of information in competitive markets. Journal of Economic Theory, 22(3), 477-498. http://dx.doi.org/10.1016/0022-0531(80)90056-3

Jelinck, F., \& Mercer, R. L. (1980). Interpolated Estimation of Markov Source Parameters from Sparse Data. In Proceedings of the Workshop on Pattern Recognition in Practice. North-Holland, Amsterdam, The Netherlands.

Lee, C., Shie, F. S., \& Chang, C. Y. (2010). How close a relationship does a capital market have with other such markets?. Pacific-Basin Finance Journal, (20), 349-362.

McKenzie, M.D., Brailsford, T. J., \& Faff, R. W. (2001). New insights into the impact of the introduction of futures trading on stock price volatility. Journal of Futures Markets, 21(3), 237-255.

Pilar, C., \& Rafael, S. (2002). Does derivatives trading destabilize the underlying assets? Evidence from the Spanish stock market. Applied Economics Letters, 9(2), 107-110. http://dx.doi.org/10.1080/13504850110049441

Stock, J. H., \& Watson, M. W. (2011). Dynamic factor models. Oxford Handbook of Economic Forecasting. Oxford University Press, USA, pp. 35-59. http://dx.doi.org/10.1093/oxfordhb/9780195398649.013.0003

Wang, S. S., Wei, L., \& Cheng, T. W. (2009). The impact of H share derivatives on the underlying equity market. Review of Quantitive Finance and Accounting, 32, 235-267. http://dx.doi.org/10.1007/s11156-008-0094-7

White, H. (1984). Asymptotic theory for econometricians. Academic press.

Wurgler, J. (2000). Financial markets and the allocation of capital. Journal of Financial Economics, 58(1), 187-214. http://dx.doi.org/10.1016/S0304-405X(00)00070-2

Yang, L. X., Lee, C. N., \& Shie, F. S. (2014). How close a relationship does a capital market have with other such markets? A reexamination based on the equal variance test. Pacific-Basin finance Journal, (26), 198-226. http://dx.doi.org/10.1016/j.pacfin.2013.12.007

\section{Note}

Note 1. For the definitions of mixing and martingale, see Chapter 3 of White (2001). 